\title{
Reduced anogenital distance, hematuria and left renal hypoplasia in a patient with 13q33.1-34 deletion: case report and literature review
}

Xue He, Huijun Shen, Haidong Fu, Chunyue Feng, Zhixia Liu, Yanyan Jin and Jianhua Mao*

\begin{abstract}
Background: 13q33-q34 microdeletions are rare chromosomal aberrations associated with a high risk of developmental disability, facial dysmorphism, cardiac defects and other malformation of organs. It is necessary to collect and report evidence of this rare chromosome mutation to improve the prognosis of this rare disease.

Case presentation: We report a patient harboring an $11.56 \mathrm{Mb}$ microdeletion at 13q33.1-34 region, which contains about 30 OMIM genes. Besides the common clinical manifestations such as facial dysmorphism, developmental delay, intellectual disability, epilepsy, and congenital heart disease, she also suffered from a reduced anogenital distance, hematuria and left renal hypoplasia. Most related cases were characterized by facial deformity and heart defects, but there were few reports on renal malformation, especially regarding renal hypoplasia with hematuria.

Conclusion: We have reported a patient suffering from a reduced anogenital distance, hematuria and left renal hypoplasia. A de novo $11.56 \mathrm{Mb}$ deletion ranging from 13q33.1 to $13 q 34$ (Chr13:103542220-115,106,996) was found by SNP-array analysis. It might be the first time for hematuria and renal hypoplasia to be reported as symptoms of 13q33-q34 deletion syndrome Neurodevelopmental disability, heart defects and urogenital/anorectal anomalies may be resulted from common or overlapping regions of deletion in chromosome bands 13q33.1-q34 and may share a common molecular mechanism.
\end{abstract}

Keywords: 13q deletion syndrome, 13q33-34 deletion, Chromosome 13, Renal hypoplasia, Congenital heart disease

\section{Background}

13q deletion syndrome is a rare genetic disorder caused by the deletion of the long arm of chromosome 13 [1, 2]. It was first reported in patients with mental and growth retardations in 1963 [3]. Patients with 13q deficiency exhibit a variety of phenotypic characteristics, including intellectual disability, hypotonia, developmental delays, microcephaly, central nervous system abnormalities, microphthalmia, heart

\footnotetext{
* Correspondence: maojh88@zju.edu.cn

Department of Nephrology, National Clinical Research Center For Child Health, The Children's Hospital, Zhejiang University School of Medicine, \#57 Zhugan Lane, Hangzhou, Zhejiang Province 310003, P.R. China
}

defects, urogenital abnormalities, and limb abnormalities $[1,4]$. According to the sizes and locations of the deletions, they can be divided into three types: 1) deletions of chromosome regions near the band 13q32; 2) deletions of chromosome band 13q32; and 3) deletions of distal band 13q33-34. 13q deletion syndrome is a rare genetic disorder, especially the third type described above [5]. With the development of chromosomal microarray analysis technology, increasing number of microdeletions are being identified [6]. However, until now, a limited number of cases for 13q33-q34 deletion syndrome were reported in the literature and most

(c) The Author(s). 2020 Open Access This article is licensed under a Creative Commons Attribution 4.0 International License, which permits use, sharing, adaptation, distribution and reproduction in any medium or format, as long as you give appropriate credit to the original author(s) and the source, provide a link to the Creative Commons licence, and indicate if changes were made. The images or other third party material in this article are included in the article's Creative Commons licence, unless indicated otherwise in a credit line to the material. If material is not included in the article's Creative Commons licence and your intended use is not permitted by statutory regulation or exceeds the permitted use, you will need to obtain permission directly from the copyright holder. To view a copy of this licence, visit http://creativecommons.org/licenses/by/4.0/. The Creative Commons Public Domain Dedication waiver (http://creativecommons.org/publicdomain/zero/1.0/) applies to the data made available in this article, unless otherwise stated in a credit line to the data. 
related cases were characterized by facial deformity or heart defects $[2,7,8]$. Moreover, there were few reports on renal malformations. Here we described a seven years old girl harboring an $11.56 \mathrm{Mb}$ microdeletion at 13q33-34 region with facial abnormalities, hypotonia, growth delay, psychomotor developmental delay, epilepsy, reduced anogenital distance, hematuria and left renal hypoplasia.

\section{Case presentation}

The patient was a 7-year-old female born at 41 weeks of gestation by normal vaginal delivery. A "Double Bubble" sign was observed by fetal ultrasound at 39 weeks of gestation. Her birth weight was $3050 \mathrm{~g}$. Her parents were healthy and unrelated and her mother denied any history of taking teratogenic drugs, heavy drinking or diabetes during pregnancy. The girl was the first child of the family and had no siblings. She had normal meconium but was found to have hypotonia, weak crying, and facial abnormalities after birth. Muscular ventricular septal defect $(2.5 \mathrm{~mm})$ and patent ductus arteriosus $(1.4 \mathrm{~mm})$ were detected in the patient by cardiac ultrasound. In addition, the patient failed the hearing screening and the brainstem auditory evoked potential (BAEP) test. Chromosome G-banding analysis was carried out in the neonatal period and showed a normal female karyotype. As she grew up, her motor and mental development significantly lagged behind her peers. Cytogenetic analysis and SNP-array analysis were performed when she was two years old. The chromosome analysis of the girl revealed a deletion of the long arm of chromosome 13 (Fig. 1), described as 46, XX, del (13)(q33.1). Compared with the Database of Genomic Variants (DGV), a de novo $11.56 \mathrm{Mb}$ deletion ranging from 13q33.1 to 13q34 (Chr13:103542220-115,106,996) was found. This chromosome region contains about 30 OMIM genes, including SLC10A2, DAOA, EFNB2, ARGLU1, LIG4, TNFSF13B, IRS2, COL4A1, COL4A2, CARS2, ING1, ARHGEF7, SOX1, ATP11A, MCF2L, F7, F10, PROZ, PCIDI, CUL4A, LAMPA, ADPRHL1, TFDP1, ATP4B, GRK1, GAS6, RASA3, and UPF3A. As she grew up, microscopic hematuria and urinary tract infections were detected by routine urine tests when she suffered from a fever, with her red blood cell count being 20-50/HP. She suffered her first grand mal epileptic seizure when she was 6 years old and was treated with valproate since then. In October 2019, when she was about 7 years old, she was hospitalized in our department and a thorough physical examination was carried out. Her blood pressure was normal, and her height and weight were $120.0 \mathrm{~cm}$ (P25) and $20.0 \mathrm{~kg}$ (P25) respectively. She had a flat and leaning head, hypertelorism, malformed ears, flat and broad bridge, micrognathia, and transverse palmar crease on both hands. In addition, the distances between her urethra, vagina and anus were shorter than normal (Fig. 2). She had congenital dislocation of the left hip joint and she was incapable of walking independently. Her psychomotor milestones were delayed with mental retardation and she suffered from incontinence. Routine blood, liver function and renal function tests were normal, the tests on complement C3, antinuclear antibody (ANA), antineutrophilic cytoplasmic antibody (ANCA), and HBV

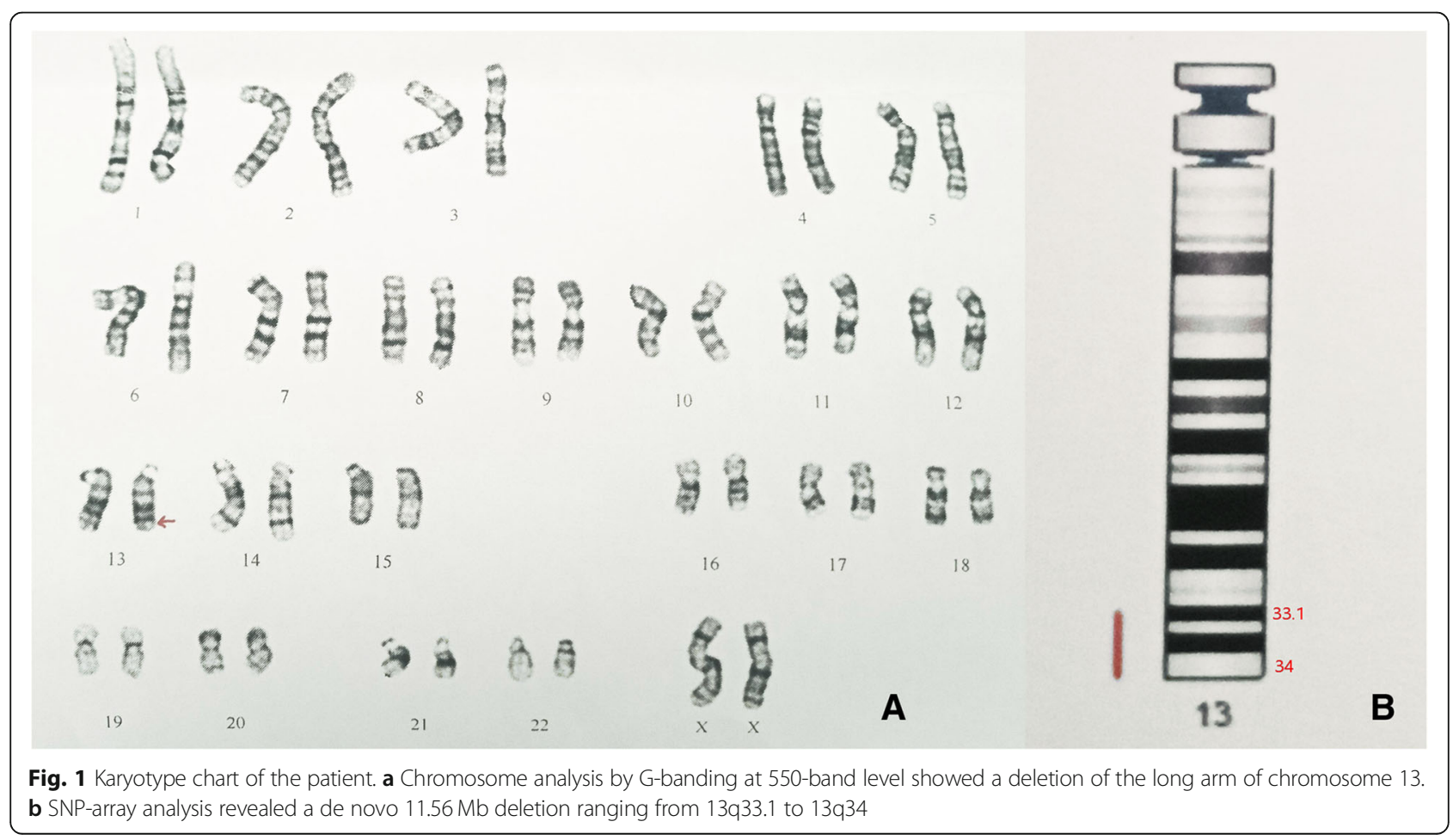




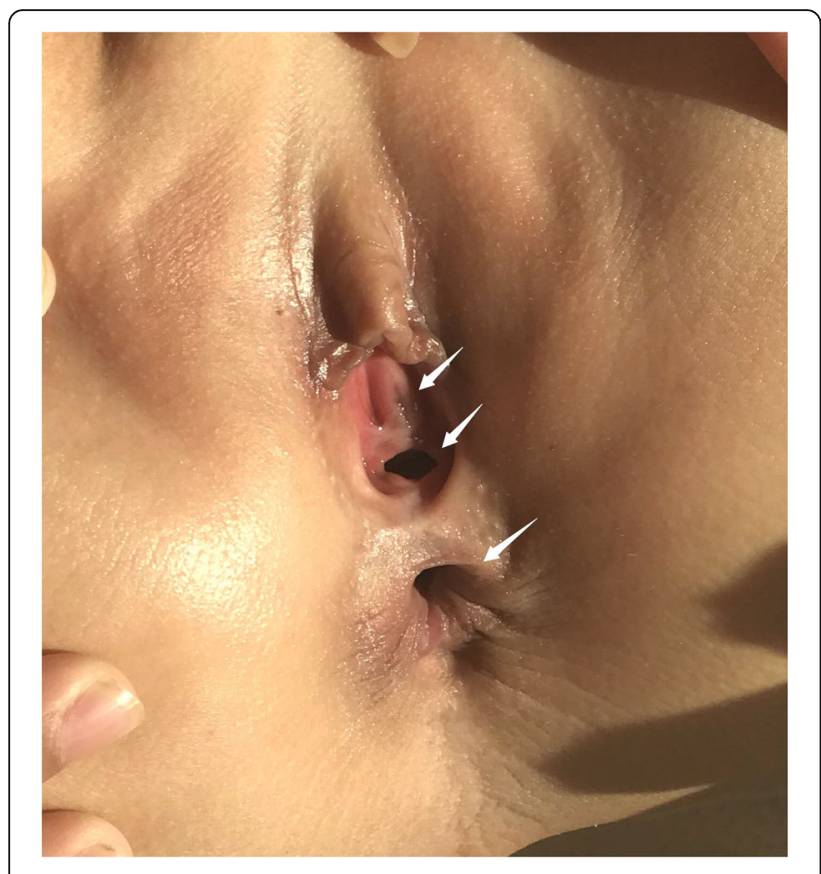

Fig. 2 Reduced anogenital distance

test also showed no abnormalities. The test on urinary microprotein was normal with a urine protein/creatinine ratio of 0.16 and a urinary calcium/creatinine ratio of 0.01 . During this time, a cardiac ultrasound was performed again but only found mild tricuspid regurgitation with no VSD or PDA. Uterine and ovarian ultrasound scans were normal and renal vein ultrasound showed no symptom of left renal vein entrapment syndrome. Renal ultrasound scans indicated that the left kidney was small with a size of $4.2 \mathrm{~cm} \times$ $1.9 \mathrm{~cm}$ (less than two standard deviations), while the right kidney was $8.2 \mathrm{~cm} \times 4.5 \mathrm{~cm}$ in size. The renal MRI showed left renal hypoplasia and hydronephrosis (Fig. 3). Dynamic renal function imaging showed that the glomerular filtration rate (GFR) of the left kidney was $19.34 \mathrm{ml} / \mathrm{min}$ and the GFR of the right kidney was $85.81 \mathrm{ml} / \mathrm{min}$. To further investigate the cause of renal miniaturization and hematuria, a renal vascular contrast-enhanced ultrasonography and a contrastenhanced voiding urosonography (ceVUS) were performed. The results suggested that (1) The left kidney was smaller than normal, and the left renal artery was relatively thin (diameter of the left renal artery was $0.10 \mathrm{~cm}$, while that of the right renal artery was $0.30 \mathrm{~cm}$ ). The enhancement degree of contrast-enhanced ultrasound of the left kidney was weak compared to the right. (2) The left lower ureter was slightly dilated and a mild vesicoureteral reflux (grade I) of the left side was detected. Nitrofurantoin $(1 \mathrm{mg} / \mathrm{kg} / \mathrm{d}$ was given every night to avoid recurrent urinary tract infection and the patient did not suffer from any urinary tract infection in the past few months. However, microscopic hematuria was detected every time during routine urine tests. Because of the unilateral renal hypoplasia, a kidney biopsy was not performed.

\section{Discussion and conclusions}

Chromosomal microarray analysis (CMA) is a technology comprising array-based comparative genome hybridization and single-nucleotide polymorphism arrays. It is used for the detection of clinically significant microdeletions or duplications with high sensitivity for submicroscopic aberrations $[6,9]$. The chromosome analysis of our patient revealed a deletion of the long arm of chromosome 13. The molecular karyotype was described as arr 13q33.1q34(103542220-115, $106,996) \times 1$ by the SNP-array, and the chromosome Gbanding analysis showed a normal female karyotype in the neonatal period. Our case once again demonstrated the important role of CMA. We strongly urge patients with facial deformities, developmental delay and multiple congenital anomalies to undergo the CMA test as early as possible, despite getting normal results from the chromosome karyotype tests.

Deletions of chromosome bands 13q33-34 are rare. Majority of patients with such deletions have mental retardation, microcephaly, and distinct facial features [4].
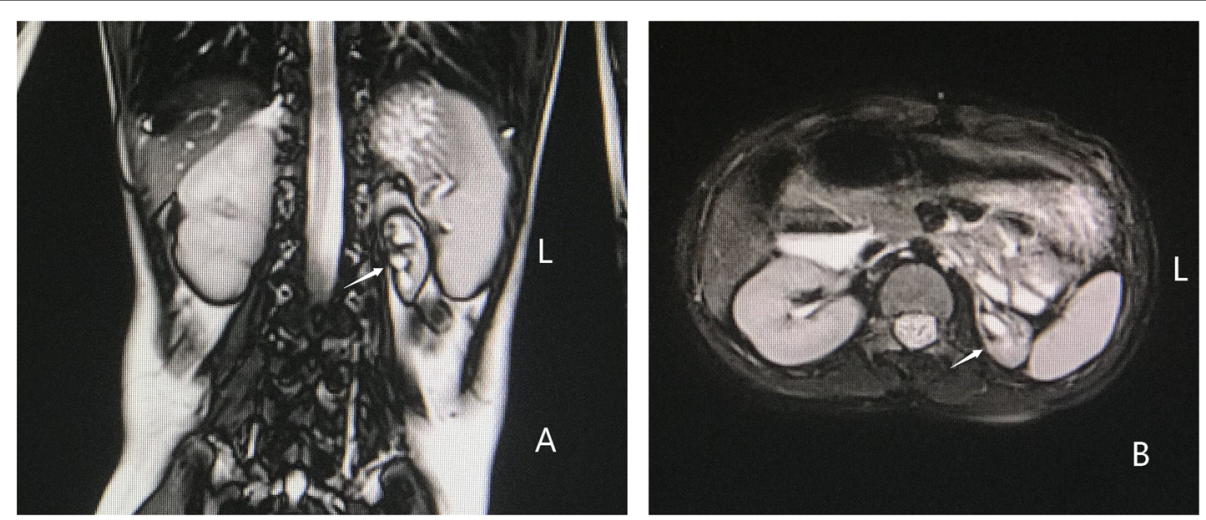

Fig. 3 Renal MRI of the patient, viewing the kidney in the coronal plane (a) and the transverse plane (b). The left kidney was small in size; the boundary between cortex and medulla was not clear; renal pelvis and calyces dilation was detected. The right kidney was normal in shape and size 
This study reports a patient with a de novo $11.56 \mathrm{Mb}$ deletion ranging from $13 q 33.1$ to $13 q 34$ (Chr13: $103542220-115,106,996)$ which is a chromosome region containing about 30 OMIM genes, including eight OMIM morbid genes: SLC10A2, LIG4, COL4A1, COL4A2, ING1, F7, F10 and GRK1. The patient suffered from a reduced anogenital distance, hematuria and left renal hypoplasia in addition to the common clinical features of mental retardation, facial abnormalities, and congenital heart diseases.

Genitourinary/anorectal anomalies in the 13q deletion syndrome are rare and they vary in severity and manifestation. Anal atresia, hypospadias and perineal fistula were recorded to be observed in male patients $[7,10]$. However, only a few cases were identified in females, and they were often misdiagnosed as anal atresia or vaginal fistula $[8,11]$. Joanna et al. [8] reported that 13q33-34 might contain a gene for male genital development. The non-morbid OMIM gene ephrin B2 (EFNB2), located in 13q33.3, was recognized recently as a strong candidate gene responsible for hypospadias and anorectal anomalies in $13 q$ deletion syndrome in severl studies $[8,12]$. There was no urethrovaginal fistula or any other abnormalities in our patient. The uterine and ovarian ultrasound scans were normal but the patient had a reduced anogenital distance.

There were less than five cases reported with renal malformation [8, 12]. Jonna et al. [8] reported a boy suffering from malformed genitalia (penoscrotal transposition and hypospadias) and his ultrasound examinations showed pelvic displacement of the right kidney. Kuhnle $\mathrm{U}$ et al. [12] reported a boy with penoscrotal inversion and hypospadias and his B-mode ultrasound of the urogenital tract revealed the absence of the left kidney. For our patient, urological ultrasound and MRI revealed unilateral renal hypoplasia. Microscopic hematuria was detected by the routine urine tests. The girl did not have any history of acute kidney injury or usage of nephrotoxic drugs during her infancy. Causes of hematuria such as idiopathic hypercalciuria, urolithiasis, left renal vein compression syndrome and urinary tract infections were excluded by detailed clinical examinations. We postulated that the underlying renal abnormality associated with $13 \mathrm{q}$ deletion might be the cause of hematuria. We believed that there might be a relation between renal agenesis and 13q33-q34 deletion. This region is likely to contain one or more developmental genes and deletions or haploinsufficiency of these genes can result in genitourinary system malformations. The pathogenesis of renal malformation has not been elucidated but many researchers are paying more attention to gene mutation and copy number variation to be the possible causes In addition to genetic factors, environmental factors during pregnancy can also influence kidney development. These factors involve taking teratogenic drugs during pregnancy, heavy drinking and diabetes [13-15]. Currently, the specific molecular mechanism of renal malformation is still pending further investigation. Our case may be a clue to the mechanism of renal agenesis.

Previously reported cases and studies suggested that 13q33.1-34 deletion was closely associated with congenital heart diseases (CHD) $[2,16,17]$ and approximately $50 \%$ of the patients had CHD [16]. CHD in $13 q$ deletion syndrome is more complex than in isolated cases and of the complexity comes from the presence of DORV, Tetralogy of Fallot, at least 2 heart anomalies in one patient or rare type complex heart anomalies $[2,7,16,17]$. The complexity suggests that multiple genes may be involved in its pathogenesis. Huang et al. [2] hypothesized that a $6 \mathrm{Mb}$ region of 13q33.1-q34 may contain a critical region for cardiac development, and some researchers proposed COL4A1 and COL4A2 to be the possible candidate genes. These two OMIM genes may contribute to the development of cardiovascular diseases $[2,7,18-20]$. COL4A1 and COL4A2 are one of three pairs of paralogous genes that constitute type IV collagen. These two genes are ubiquitously expressed in the basement membrane, during early stages of development. Mutations of COL4A1 and COL4A2 are increasingly recognized as causes of multisystem disorders [21]. The spectrum of COL4A1related disorders includes: 1) brain small vessel disease 1 with or without ocular anomalies, 2) hereditary angiopathy with nephropathy, aneurysms, and muscle cramps, 3) susceptibility to intracerebral hemorrhage, 4) tortuosity of retinal arteries, 5) autosomal dominant pontine microangiopathy and leukoencephalopathy [22]. The spectrum of COL4A2-related disorders includes brain small vessel disease $2[23,24]$ and susceptibility to intracerebral hemorrhage [25]. Environmental factors or other genetic modifications may also influence the phenotypic expression and the severity of the organs' involvement in the related disease. The studies by Schenke Leyland et al. [26] and Hanson et al. [20] demonstrated that type IV collagen played a vital role in early cardiac development. Nonetheless, there was still no direct evidence that could prove the exact relationship between CHD and these 2 genes. Approximately 50\% of patients with deletions of COL4A1 and COL4A2 did not have congenital heart defects but our patient belonged to the other $50 \%$ who did suffer from CHD (in her case were VSD and PDA). However, her heart defects healed spontaneously during the process of her development. Hence, we believe that children with chromosome abnormalities can also spontaneously recover from mild congenital heart disease the same way as normal children.

Most children with chromosome disorders also have mental retardation and they usually suffer from micturition incontinence. Therefore one should be aware of the 
possibility of recurrent urinary tract infections and vesicoureteral reflux. Contrast-enhanced voiding urosonography (ceVUS) is a dynamic imaging technique, which is often indicated to depict vesicoureteral reflux (VUR) [27]. ceVUS has become routine screening for VUR in children in Europe and it was shown to be capable of detecting higher grades of reflux in addition to being more sensitive compared to voiding cystourethrography (VCUG) [27, 28]. However, ceVUS has not been widely used in China. In deference to the wishes of the patient's parents, we performed this technique and detected slight reflux. In addition, ionizing radiation was avoided.

In conclusion, we reported a patient with a de novo $11.56 \mathrm{Mb}$ microdeletion ranging from $13 \mathrm{q} 33.1$ to $13 \mathrm{q} 34$ (Chr13:103542220-115,106,996). Besides the common clinical manifestations such as facial dysmorphism, developmental delay, intellectual disability, epilepsy, and congenital heart disease, she also suffered from a reduced anogenital distance, hematuria and left renal hypoplasia. It mighe be the first time for hematuria and renal hypoplasia to be reported as symptoms of 13q33q34 deletion. Neurodevelopmental disability, heart defects and urogenital/anorectal anomalies may be resulted from common or overlapping regions of deletion in chromosome bands 13q33.1-q34 and may share a common molecular mechanism. However, the molecular mechanism is still not very clear until now. With the development of CMA technology, increasing number of microdeletions are being identified and this will provide a greater understanding of the molecular mechanisms of chromosome 13q deletion syndrome.

\section{Abbreviations}

CMA: Chromosomal microarray analysis; SNP: Single-nucleotide polymorphism; CHD: Congenital heart disease; DORV: Double outlet right ventricle; ceVUS: Contrast-enhanced voiding urosonography

\section{Acknowledgements}

The authors wish to thank the patient and her parents for their kind collaboration and their contribution to this report.

\section{Authors' contributions}

$\mathrm{XH}, \mathrm{HS}$ and $\mathrm{JM}$ analyzed the data, and wrote the manuscript. $\mathrm{HF}, \mathrm{XH}, \mathrm{CF}, \mathrm{ZL}$ and YJ contributed to clinical and instrumental data. All authors read and approved the final manuscript.

\section{Funding}

This study was supported by the National Natural Foundation of China (81770710), Key Research and Development Plan of Zhejiang Province (2019C03028), the Major projects jointly constructed by the Zhejiang province and National Health Commission (WKJ-ZJ-1908), the Natural Science Foundation of Zhejiang Province (LQ18H050001), and the Medicine \&Health Technology Project of Zhejiang Province (2018RC007).

\section{Availability of data and materials}

The data of the current study are available from the corresponding author on reasonable request.

\section{Ethics approval and consent to participate}

Written informed consents were obtained from the parents of the patients for the publication of this study. This study was in compliance with the
Helsinki Declaration and was approved by the Ethical Review Board of The Children's Hospital of Zhejiang University School of Medicine.

\section{Consent for publication}

The parents of the patients consented to the publication of the case and any accompanying images with written consent.

\section{Competing interests}

The authors declare that they have no competing interests.

Received: 24 March 2020 Accepted: 12 June 2020

Published online: 02 July 2020

\section{References}

1. Sagi-Dain L, Goldberg Y, Peleg A, Sukenik-Halevy R, Sofrin-Drucker E, Appelman Z, Josefsberg BYS, Ben-Shachar S, Vinkler C, Basel-Salmon L, et al. The rare 13q33-q34 microdeletions: eight new patients and review of the literature. Hum Genet. 2019;138(10):1145-53.

2. Huang $C$, Yang YF, Yin N, Chen JL, Wang J, Zhang H, Tan ZP. Congenital heart defect and mental retardation in a patient with a 13q33.1-34 deletion. Gene. 2012;498(2):308-10.

3. Lele KP, Penrose LS, Stallard HB. Chromosome deletion in a CASE of retinoblastoma. Ann Hum Genet. 1963;27:171-4.

4. Bellucco FT. Rodrigues de Oliveira-junior H, Santos Guilherme R, Bragagnolo $\mathrm{S}$, Alvarez Perez AB, Ayres Meloni V, Melaragno Ml: deletion of chromosome 13 due to different rearrangements and impact on phenotype. Mol Syndromol. 2019;10(3):139-46.

5. Brown $S$, Gersen S, Anyane-Yeboa K, Warburton D. Preliminary definition of a "critical region" of chromosome 13 in q32: report of 14 cases with 13q deletions and review of the literature. Am J Med Genet. 1993;45(1):52-9.

6. Resta N, Memo L. Chromosomal microarray (CMA) analysis in infants with congenital anomalies: when is it really helpful? J Matern-Fetal Neonatal Med. 2012;25(Suppl 4):124-6.

7. Wang YP, Wang DJ, Niu ZB, Cui WT. Chromosome 13q deletion syndrome involving 13q31qter: a case report. Mol Med Rep. 2017;15(6):3658-64.

8. Walczak-Sztulpa J, Wisniewska M, Latos-Bielenska A, Linne M, Kelbova C, Belitz B, Pfeiffer L, Kalscheuer V, Erdogan F, Kuss AW, et al. Chromosome deletions in 13q33-34: report of four patients and review of the literature. Am J Med Genet A. 2008;146a(3):337-42.

9. Slavotinek AM. Novel microdeletion syndromes detected by chromosome microarrays. Hum Genet. 2008;124(1):1-17.

10. Bartsch O, Kuhnle U, Wu LL, Schwinger E, Hinkel GK. Evidence for a critical region for penoscrotal inversion, hypospadias, and imperforate anus within chromosomal region 13q32.2q34. Am J Med Genet. 1996;65(3):218-21.

11. Garcia NM, Allgood J, Santos LI, Lonergan D, Batanian JR, Henkemeyer M, Bartsch O, Schultz RA, Zinn AR, Baker LA. Deletion mapping of critical region for hypospadias, PENOSCROTAL transposition and imperforate anus on human chromosome 13. J Pediatr Urol. 2006;2(4):233-42.

12. Kuhnle U, Bartsch O, Werner W, Schuster T. Penoscrotal inversion, hypospadias, imperforate anus, facial anomalies, and developmental delay: definition of a new clinical syndrome. Pediatr Surg Int. 2000;16(5-6):396-9.

13. Radhakrishna V, Govindarajan KK, Sambandan K, Jindal B, Naredi B. Solitary functioning kidney in children: clinical implications. Jornal brasileiro de nefrologia. 2018;40(3):261-5.

14. Westland R, Schreuder MF, van Goudoever JB, Sanna-Cherchi S, van Wijk JA. Clinical implications of the solitary functioning kidney. Clin J Am Soc Nephrol. 2014;9(5):978-86.

15. Laurichesse Delmas H, Kohler M, Doray B, Lemery D, Francannet C, Quistrebert J, Marie C, Perthus I. Congenital unilateral renal agenesis: prevalence, prenatal diagnosis, associated anomalies. Data from two birthdefect registries. Birth Defects Res. 2017;109(15):1204-11.

16. McMahon CJ, Breathnach C, Betts DR, Sharkey FH, Greally MT. De novo interstitial deletion 13933.3934 in a male patient with double outlet right ventricle, microcephaly, dysmorphic craniofacial findings, and motor and developmental delay. Am J Med Genet A. 2015;167A(5):1134-41.

17. Yang YF, Ai Q, Huang C, Chen JL, Wang J, Xie L, Zhang WZ, Yang JF, Tan ZP. A 1.1 Mb deletion in distal $13 q$ deletion syndrome region with congenital heart defect and postaxial polydactyly: additional support for a CHD locus at distal 13934 region. Gene. 2013;528(1):51-4.

18. Ballarati L, Rossi E, Bonati MT, Gimelli S, Maraschio P, Finelli P, Giglio S, Lapi E, Bedeschi MF, Guerneri S, et al. 13q deletion and central nervous system 
anomalies: further insights from karyotype-phenotype analyses of 14 patients. J Med Genet. 2007:44(1):e60.

19. Quelin C, Bendavid C, Dubourg C, de la Rochebrochard C, Lucas J, Henry C, Jaillard S, Loget $P$, Loeuillet $L$, Lacombe $D$, et al. Twelve new patients with $13 q$ deletion syndrome: genotype-phenotype analyses in progress. Eur J Med Genet. 2009;52(1):41-6.

20. Hanson KP, Jung JP, Tran QA, Hsu SP, lida R, Ajeti V, Campagnola PJ, Eliceiri KW, Squirrell JM, Lyons GE, et al. Spatial and temporal analysis of extracellular matrix proteins in the developing murine heart: a blueprint for regeneration. Tissue Eng A. 2013;19(9-10):1132-43.

21. Favor J, Gloeckner CJ, Janik D, Klempt M, Neuhäuser-Klaus A, Pretsch W, Schmahl W, Quintanilla-Fend L. Type IV Procollagen missense mutations associated with defects of the eye, vascular stability, the brain, kidney function and embryonic or postnatal viability in the mouse, <em $>$ Mus musculus $</$ em $>$ : an extension of the $<$ em $>\mathrm{Co} \mid 4 \mathrm{a} 1</$ em $>$ allelic series and the identification of the first two $<\mathrm{em}>\mathrm{Col} 4 \mathrm{a} 2</ \mathrm{em}>$ mutant alleles. Genetics. 2007;175(2):725-36.

22. Shan LD, Peng J, Xiao H, Wu LW, Duan HL, Pang N, Miriam K, Yin F. Clinical features and COL4A1 genotype of a toddler with hereditary angiopathy with nephropathy, aneurysms and muscle cramps syndrome. Zhongguo Dang Dai Er Ke Za Zhi. 2019;21(8):754-60.

23. Cavallin M, Mine M, Philbert M, Boddaert N, Lepage JM, Coste T, LopezGonzalez V, Sanchez-Soler MJ, Ballesta-Martinez MJ, Remerand G, et al. Further refinement of COL4A1 and COL4A2 related cortical malformations. European journal of medical genetics. 2018;61(12):765-72.

24. Meuwissen ME, Halley DJ, Smit LS, Lequin MH, Cobben JM, de Coo R, van Harssel J, Sallevelt S, Woldringh G, van der Knaap MS, et al. The expanding phenotype of COL4A1 and COL4A2 mutations: clinical data on 13 newly identified families and a review of the literature. Genet Med. 2015;17(11):843-53.

25. Jeanne M, Labelle-Dumais C, Jorgensen J, Kauffman WB, Mancini GM, Favor J, Valant V, Greenberg SM, Rosand J, Gould DB. COL4A2 mutations impair COL4A1 and COL4A2 secretion and cause hemorrhagic stroke. Am J Hum Genet. 2012;90(1):91-101.

26. Schenke-Layland K, Nsair A, Van Handel B, Angelis E, Gluck JM, Votteler M, Goldhaber II, Mikkola HK, Kahn M, Maclellan WR. Recapitulation of the embryonic cardiovascular progenitor cell niche. Biomaterials. 2011;32(11):2748-56.

27. Papadopoulou F, Anthopoulou A, Siomou E, Efremidis S, Tsamboulas C, Darge K. Harmonic voiding urosonography with a second-generation contrast agent for the diagnosis of vesicoureteral reflux. Pediatr Radiol. 2009:39(3):239-44.

28. Darge K. Voiding urosonography with US contrast agent for the diagnosis of vesicoureteric reflux in children: an update. Pediatr Radiol. 2010;40(6):956-62..

\section{Publisher's Note}

Springer Nature remains neutral with regard to jurisdictional claims in published maps and institutional affiliations.

Ready to submit your research? Choose BMC and benefit from:

- fast, convenient online submission

- thorough peer review by experienced researchers in your field

- rapid publication on acceptance

- support for research data, including large and complex data types

- gold Open Access which fosters wider collaboration and increased citations

- maximum visibility for your research: over $100 \mathrm{M}$ website views per year

At BMC, research is always in progress.

Learn more biomedcentral.com/submissions 